\title{
АНАЛИЗ КОМБИНИРОВАННОЙ ТЕРАПИИ РЕКОМБИНАНТНЫМ ФОЛЛИКУЛОСТИМУЛИРУЮЩИМ ГОРМОНОМ И ХОРИОНИЧЕСКИМ ГОНАДОТРОПИНОМ У МАЛЬЧИКОВ С ГИПОГОНАДОТРОПНЫМ ГИПОГОНАДИЗМОМ: СЕРИЯ КЛИНИЧЕСКИХ СЛУЧАЕВ
}

\author{
Латышев О.Ю., Кокорева К.Д., Окминян Г.Ф., Киселева Е.В., Самсонова Л.Н. \\ Кафедра детской эндокринологии ФГБОУ ДПО РМАНПО Минздрава России, Москва
}

ЦЕЛЬ: оценить адекватность комбинированной заместительной терапии гипогонадотропного гипогонадизма у мальчиков.

МАТЕРИАЛЫ И МЕТОДЫ: включены 1 пациент с изолированным (№1) и 2 пациента с гипогонадотропным гипогонадизмом (ГГ) в составе гипопитуитаризма (ГП) (№ 2, 3). Проведена оценка антропометрических данных (SDS роста, SDS отклонения от целевого роста, Auxology); полового развития по Тапnеr; уровня тестостерона (Т), лютеинизирующего гормона (ЛГ), фолликулостимулирующего гормона (ФСГ), ингибина В, антимюллерова гормона (АМГ), объема гонад (ОГ) (орхидометр Prader, эховолюметрия), костного возраста (КВ), теста с аналогом ГнРГ (трипторелин 0,1 мг), хорионическим гонадотропином (ХГч) (2000/ $\mathrm{M}^{2}$ ), МРТ гипофиза с контрастированием, молекулярно-генетическое исследование (№1-панель «гипогонадизм», № 2, 3 - «гипофизарная» панель).

Схема терапии: №1,2 перед началом комбинированной заместительной гормональной терапии (ЗГТ) вводили Т (100 мг 1 раз в 30 дней №3). У №3 перед комбинированной ЗГТ-ХГч в дозе 1500 МЕ/нед №12. Далее пациенты переведены на комбинированную ЗГТ рекомбинантным фолликулостимулирующим гормоном (рФСГ) в дозе 75 МЕ в неделю и ХГч в различных режимах в зависимости от уровня Т:1000/1500/3000 МЕ в неделю. Длительность наблюдения составила 19,3土5,6 месяцев.

PЕзУЛЬТАТЫ: в допубертатном возрасте ГГ не был установлен ни у одного из пациентов. №1 - диагноз ГГ в 16 лет по обращению; №2 - в 11,9 лет - вторичный гипотиреоз (ВГ), в 12,3 - соматотропная недостаточность (СТГ-дефицит) и вторичный гипокортицизм (ВНН), ГГ установлен через 4 года после диагностики ГП; №3 - в 2,9 года - ВГ, в 3,4 года - СТГ-дефицит, 8 лет - ВНH, в 13,3 - мутация РROP-1).

К моменту начала ЗГТ: №1 - возраст 16,0 лет, рост 174 см (0,25SD, опережение ЦP 1,01SD), Tanner 1,ОГ 1,07см³ (<2 перц), Т 1,05 нмоль/л, ингибин В 50,2 пг/мл, АМГ 56,04 нг/мл, КВ 14 лет (-2,1SD). Через 24 мес ЗГТ: 18 лет, 188 см (2SD, опережение ЦР 1,43SD), Tanner 5,ОГ 9,14 см³ (15 перц), Т 16,05 нмоль/л, ингибин В 153,1 пг/мл, АМГ 10,56 нг/мл, КВ - 15,5 лет (>-2 SD). №2 перед ЗГТ: возраст 16,3 лет, рост 172,5 (-0.24SD, отставание от ЦР-0,9SD, Tanner 1,ОГ 3,6см³ (<2 перц), Т-0,94 нмоль/л, ингибин В-114,5 пг/мл, АМГ30,54 нг/мл, КВ - 13,5 лет (-2,6SD). Через 21 мес ЗГТ: 17,9 лет, 184,5 см (1,48, опережение ЦP 0,83SD), Tanner 4-5,ОГ 7см3 (3 перц), Т 20,3 нмоль/мл,ингибин В 131,8 пг/мл, АМГ — 6,01 нг/мл, КВ 13,5 (<-4 SD). №3 перед ЗГТ: возраст 15,3 года, 165 см (-0,68SD, отставание от ЦР-1,03SD), Tanner 1,ОГ 1,5см³ (<2 перц), Т<0.087 нмоль/л, ингибин В-22,3 пг/мл, АМГ 22,17 нг/мл, КВ - 14 лет 14 лет (-0.94SD). Через 13 мес 3ГТ: 16,5 лет, 174,5 см (0,15, отставание от ЦР-0,27SD), Tanner 4, ОГ 4,5 см³ (<2 перц), Т - 18 нмоль/л, ингибин В 152 пг/мл, АМГ 17,58 нг/мл, КВ на 14,5 лет (-1,84 SD).

ВыВоДЫ: позднее начало ЗГТ имело место как при изолированном ГГ, так и в случае ГГ в составе ГП. Причины несвоевременной терапии: отсутствие «больших» симптомов гипогонадизма-микропениса, крипторхизма у всех пациентов. Терапия ХГч была эффективной, что нашло отражение в формировании вторичных половых признаков, достижении пубертатных уровней Т и снижении АМГ. Терапия рФСГ также оказалась эффективной, что подтверждается достижением пубертатного ОГ и повышением уровня ингибина В. При установлении ГП необходимо выявлять ГГ с применением современных методов диагностики (ингибин В, АМГ) и своевременно инициировать терапию. 